\title{
A LETRA E A VIDA: DESCOMPASSOS ENTRE COTIDIANO E BUROCRACIA NAS POLÍTICAS PARA A POPULAÇÃO DE RUA
}

THE LETTER AND LIFE: MISMATCHES BETWEEN DAILY LIFE AND BUREAUCRACY IN POLICIES FOR THE HOMELESS

\section{LA LETRA Y LA VIDA: DESAJUSTES ENTRE LA VIDA COTIDIANA Y LA BUROCRACIA EN LAS POLÍTICAS PARA LA POBLACIÓN SIN HOGAR}

\author{
Maria Teresa Nobre* \\ Irlys Alencar Firmo Barreira ${ }^{*}$
}

\begin{abstract}
RESUMO
O artigo aborda a população de rua como caso emblemático para discutir a relação entre cotidiano e burocracia, apresentando as tensões entre os modos de vida e o funcionamento institucional das políticas públicas a ela destinadas, em duas capitais do Nordeste brasileiro. A partir de narrativas de pessoas em situação de rua, registros de observação participante/itinerante e entrevistas com trabalhadores, problematiza a distância entre a letra (a burocracia) e a vida (o cotidiano), e a relação entre tempos e espaços regulamentados, evidenciando como, fora dos muros institucionais, a vida cotidiana é praticada na sua singularidade, porém excluída do direito à cidade. Nesse contexto, a cidade é pensada como polis, concluindo-se que os desafios da rua são os desafios da cidade: agregar histórias e dar suporte às diferenças.
\end{abstract}

Palavras-chave: População de rua. Cotidiano. Burocracia. Políticas públicas. Cidade.

\begin{abstract}
This paper studies the homeless population as an emblematic case to discuss the relationship between daily life and bureaucracy, displaying the tensions between living on the streets and the functioning of public policies concerning homeless people's living in two capitals in the Northeast of Brazil. Based on homeless people's narrative excerpts, participant/itinerant's observation records and workers' reports through interviews, the study problematizes the distance between the letter (bureaucracy) and life (daily
\end{abstract}

\footnotetext{
"Professora associada da Universidade Federal do Rio Grande do Norte (UFRN), Programa de Pós-Graduação em Psicologia. E-mail: teresa-nobre@uol.com.br.

"Professora titular da Universidade Federal do Ceará (UFC), Programa de Pós-Graduação em Sociologia. E-mail: irlys.firmo@ gmail.com.
} 
life) and the relation between regulated time and space, highlighting how, outside the institutional walls, the daily life is practiced in its uniqueness, but excluded from the right to the city. In this context, the city is understood as polis, concluding that the challenges on the street are the challenges of the city: aggregating stories and supporting the differences.

Keywords: Homeless. Daily life. Bureaucracy. Public policies. City.

\section{RESUMEN}

El artículo aborda la población sin hogar como caso emblemático para discutir la relación entre el cotidiano y la burocracia, presentando los conflictos entre los modos de vida y el funcionamiento institucional de las políticas públicas destinadas para estas personas, en dos capitales del Noreste brasileño. Tomando como base las narrativas de personas sin hogar, registros de observación participante/itinerante y entrevistas con trabajadores, analiza de una forma crítica los desajustes entre la letra (burocracia) y la vida (cotidiano) y la relación entre tiempos y espacios reglamentados, mostrando como fuera de los muros institucionales la vida cotidiana es practicada de manera singular, sin embargo, excluida del derecho a la ciudad. En ese contexto la ciudad es pensada como polis, concluyéndose que los desafíos de la calle son los desafíos de la ciudad: albergar historias y permitir las diferencias.

Palabras clave: Población sin hogar. Cotidiano. Burocracia. Políticas públicas. Ciudad.

\section{INTRODUÇÃO}

Cão 17 horas. Na calçada de uma unidade de acolhimento noturno para a população em situação de rua que se aglomera esperando a liberação dos portôes para entrada, João aguarda a resposta das profissionais da Abordagem Social, equipamento do Sistema Único de Assistência Social (SUAS), sobre a decisão de uma nova acolhida. Um mês antes, João havia sido expulso do serviço por ter cometido uma falta disciplinar considerada grave. De volta às ruas, passou a dormir pelas calçadas, o que levou proprietários das residências no entorno a acionarem a polícia, alegando que sua presença trazia transtornos à vizinhança, pois ele ali dormia, comia e fazia suas necessidades fisiológicas. Os policiais, entretanto, afirmaram que não se tratava de caso de polícia, pois não havia crime, e convocaram a Abordagem Social, que o encaminhou ao albergue que o expulsara. Ao fim da conversa, ao receber um retumbante "não", João, velho, sujo e louco, em sua indignação, retrucou: "Se na rua não posso ficar, se no albergue não posso entrar, será que eu preciso jogar uma pedra nessa janela 
pra ser preso? Porque parece que o presídio é o único lugar pra onde eu posso ir" (Medeiros, 2020).

A pedra que quebraria a vidraça é, para João, a ferramenta de libertação que, rompendo as normas sociais de defesa do patrimônio público, abrir-lhe-ia possibilidades de ter um pouso, ainda que, paradoxalmente, para isso perdesse sua liberdade. A prisão aparece, assim, para ele, como a única possibilidade de sobrevivência e de inclusão na vida da cidade, num país onde as formas de acolhimento de indivíduos não enquadrados em modelos padronizados percorrem caminhos inesperados, senão obtusos. João arrumou seus poucos pertences ali mesmo na calçada do albergue e passou a viver seus próximos dias na frente daquele prédio, chamado por muitos dos usuários de "semiaberto", outra alusão ao sistema prisional.

Tomar o caso da chamada população de rua como emblemático tem sua razão de ser. Trata-se de segmento que é objeto de inúmeras políticas públicas (de saúde, assistência, gênero, segurança, moradia, trabalho e renda, etc.) com as quais desenvolve relações marcadas simultaneamente pela necessidade e insatisfação. Os usuários dessas políticas são pessoas que vivem em situação de pobreza extrema, têm problemas graves de saúde, fazem uso problemático de droga; há muitos homossexuais, travestis, e o número de mulheres tem crescido; são negros e pardos em grande maioria; muitos professam outros credos, que não a religião cristã. São, portanto, as vidas mais precárias, descartáveis e excluídas e, uma vez que amalgamam tantas condições indesejáveis, tornam-se alvos preferenciais e presas fáceis da intolerância. Esta poderia ser aqui pensada não só como o mau humor cotidiano de passantes, mas as diferentes formas de violência simbólica prefiguradas de modo bem mais radical na categoria "miséria do mundo" (Bourdieu, 2012).

A condição comum de precariedade não os torna homogêneos. Frangella (2009, p. 49) apresenta os perfis diferenciados de pessoas em situação de rua, remetendo à construção de categorias que são históricas: andarilho, vagabundo e mendigo, como "marcas vivas da transversalidade errante". A partir dessas três classificações que também portam subdivisões, criam-se outros personagens que se particularizam em contextos diferentes. A autora adiciona a esses perfis os desempregados e os catadores de papel, os "mendigos por filosofia", os "loucos de rua" que, ao lado de intelectuais outsiders, empresários falidos, artistas desempregados e viciados em álcool e crack, fazem a multiplicidade da vida nas ruas. São essas categorias amplas e heterogêneas a referência para outras classificações contemporâneas como homelesse, sans abri, personas sin hogar, pessoas sem abrigo, sem-teto e população em situação de rua. Trata-se 
de nomeações baseadas no cenário das políticas sociais vigentes em diferentes países, a partir da década de 1970 (Frangella, 2009).

Para além da distinção casa versus rua, que nivela situações polarizadas, um olhar mais acurado revela que, nas ruas, são muito diferenciados os modos de vida cotidianos e a ocupação do espaço urbano, a circulação na cidade e os tempos das pessoas e das coisas que não se resumem à lógica da duração, mas a do instante (Martins, 2008), configurada em uma espacialidade que não é a do lugar, mas da passagem (Augé, 2008). A relação tempo-espaço que regula a vida da maioria dos moradores urbanos é, para essas pessoas, definida pela impermanência, pela provisoriedade, pelas urgências imediatas e acasos de cada dia, além das maneiras impensáveis de driblar a fome, o medo, o frio, o sono. Essas situações têm se mostrado praticamente ininteligíveis pelos serviços públicos que os atendem.

O estereótipo de morador de rua é a do ladrão, preguiçoso, perigoso e vagabundo. No Brasil, o medo e o rechaço ao vagabundo - aquele que é potencialmente capaz de se transformar em "vagamundo": desgarrado, mole, doente e frouxo (Machado, Loureiro, Luz, \& Muricy, 1978) -, constitui uma herança colonial utilizada para classificar loucos e pobres desvalidos, drogaditos, desempregados, ex-presidiários, andarilhos e outras designações acusatórias, que constituem atualmente a chamada população de rua. Eles são os "indesejáveis da cidade", uma classificação histórica atribuída também aos leprosos, num determinado momento, e aos retirantes das secas no Nordeste, exilados em campos de concentração a eles destinados no interior do Ceará, no início do século XX (Neves, 1995).

O higienismo, adotado como uma das ações da polícia médica, traçou as ações sanitárias e sociais esquadrinhando a cidade no plano da norma, evidenciando como as medidas de disciplina e ordenação do espaço urbano esboçam as relações entre pessoas desviantes e direito à cidade. Revelam ainda os dados históricos como as medidas de institucionalização dessa população ladeada entre outros "desviantes" foram uma alternativa aos problemas de ocupação e circulação da cidade. Impossibilitados de inserção social nos moldes vigentes, os não enquadrados deveriam ser "recuperados" pelas instituições, sobretudo caritativas e filantrópicas (Machado et al., 1978).

Nesse cenário, chama atenção a não inclusão dessa população nas políticas do Estado até o ano de 2004, quando a situação dos desabrigados ganhou visibilidade midiática nacional e internacional, por ocasião do massacre de um grupo de moradores de rua realizado por agentes policiais na Praça da Sé, em São Paulo (De Lucca, 2016). Causando impacto no âmbito da gestão pública do Município, as acusações oscilaram entre a apuração de responsabilidades 
da assistência social ou da segurança pública. No caso da assistência, a falta de responsabilidade era atribuída ao fato de que "deixava as pessoas viverem nas ruas" enquanto a segurança "permitia que elas morressem". O fato não foi apurado, e os responsáveis seguem impunes, mas a comoção por ele suscitada a partir da revolta e indignação dos próprios moradores de rua e de entidades religiosas e de direitos humanos fomentou a criação do Movimento Nacional da População de Rua. Trata-se de um processo que ultrapassou a gestão da morte, configurando, pela organização política por garantia de direitos fundamentais e inalienáveis, um novo nascimento (De Lucca, 2016).

Em 2009, o Decreto n. ${ }^{\circ}$ 7.053/2009 da Presidência da República instituiu a Política Nacional para a População em Situação de Rua (PNPSR), pela qual se preveem ações intersetoriais que contemplem o direito à moradia, assistência, trabalho, educação, saúde e segurança, entre outros. Engendrou-se também a produção de inúmeros saberes (médicos, jurídicos, assistenciais, etc.), colocando no centro do debate político a população que é seu objeto. Passada uma década, entretanto, o que efetivamente se observa é a longa distância entre o que está posto no texto da legislação e o funcionamento dos serviços voltados para essa população. A constatação não é surpreendente, considerando-se os embates entre as dimensões instituinte e instituída, próprios dos processos de institucionalização, como nos adverte a análise institucional (Lourau, 2004).

Do ponto de vista institucional, a construção de um dispositivo baseado no sentido de urgência incide sobre as formas de regulação de práticas postas à margem. De fato, com raras exceçôes, o que vemos no dia a dia dos serviços é a burocracia levada ao extremo em sua função de racionalização do trabalho, pelo controle, por meio de normas e regras típicas do exercício de poder hierárquico (Weber, 1984). A lógica da burocratização se exprime na rigidez de regulamentos, normas, sanções e restrições, inclusive de acesso, associada à falta de autonomia dos profissionais que atendem na ponta e que estão submetidos à hierarquização das gestôes, em geral, verticalizadas e pouco democráticas. $\mathrm{O}$ exercício da impessoalidade é o efeito desse processo, levando ao extremo o descompasso entre os modos de viver das pessoas e os modos de funcionamentos institucionais. Os tempos e espaços regulamentados escapam à maneira como a vida cotidiana é vivida nas ruas, destacando-se o que poderia ser designado por distância entre a letra e a vida.

Apesar da penúria dessas vidas precárias, cujas mortes sequer são consideradas dignas do luto (Butler, 2015), há práticas inventivas de viver, trabalhar, conviver e amar nas ruas, que fazem a vida possível para pessoas que muitas vezes nada mais têm a perder, porque já experimentam a morte em vida. É sobre esse 
descompasso entre lógicas de ação institucional e modos de vida que este artigo passa agora a deter-se.

\section{OS CAMPOS DA PESQUISA: ENTRE OS ITINERÁRIOS INSTITUCIONAIS E A VIDA COTIDIANA}

O trabalho de campo foi realizado pela primeira autora deste artigo, entre 2013 e 2016, em duas capitais do Nordeste brasileiro. Inicialmente, vinculouse a uma entidade de direitos humanos que apoiava o MNPR em uma das cidades. A demanda que originou a pesquisa foi a da construção de um perfil sociodemográfico e psicossocial visando a subsidiar a implantação de uma política pública local.

Em 2016, o trabalho de investigação se estendeu para outra capital do Nordeste e priorizou narrativas sobre o cotidiano: a vida social que se revela sob a repetição do que é aparentemente apenas rotineiro, com seus enigmas e lógicas significantes, a esconder sentidos e desvios do que está prescrito e determinado (Pais, 2015), suscitando um olhar atento aos "praticantes da cidade", em seus modos de inventar a vida (Certeau, 1998).

A pesquisa teve dois campos entrecruzados. O primeiro se configurou como observação itinerante, em cinco praças do Centro da cidade, mediante caminhadas, observação e registro de cenários em movimento. O segundo, por observação participante, registrou narrativas de pessoas em situação de rua, em encontros durante eventos, reuniōes, conversas informais e rodas de conversa no espaço de um projeto, que ocorreram semanalmente durante quatro meses. Por fim, foram realizadas seis entrevistas com coordenadores de projetos institucionais e políticas públicas e uma liderança do MNPR local.

Em ambas as cidades, são oferecidos à população em situação de rua Centros Pop (Centros de Referência em Assistência Social) e albergues para acolhimento noturno, da política de Assistência Social. Para o atendimento de pessoas que fazem uso de substâncias psicoativas, há os Centros de Atenção Psicossocial para Álcool e outras Drogas (CAPS AD), da rede de saúde mental. É prática comum o encaminhamento delas para comunidades terapêuticas (CT), tanto pelas entidades religiosas quanto por profissionais e gestores dessas políticas. Para os demais casos de saúde, há as equipes do Consultório na Rua, da rede de atenção básica. Em uma das capitais, outros equipamentos disponíveis são uma Pousada Social/Centro de Convivência e mais dois abrigos, sendo um para o acolhimento de famílias e outros dois para o público masculino. 
Algumas entidades da sociedade civil filantrópicas ou de assessoria ao MNPR também dispõem de alguns serviços. Em uma das cidades, o MNPR é o principal ator social que protagoniza as mudanças, com assento em alguns conselhos (de Saúde, Assistência, Habitação, etc.); na outra, esse lugar é ocupado pela Pastoral do Povo da Rua, em parceria com o MNPR.

\section{A POPULAÇÃO DE RUA EM CENAS DO COTIDIANO}

Em ambas as cidades, a concentração de pessoas em situação de rua é prevalente nos bairros centrais, onde há mais facilidade de acesso aos serviços e às possibilidades de trabalho e locomoção, não obstante o crescimento do mesmo fenômeno em bairros mais afastados e até nobres. Parte delas usa equipamentos públicos ou filantrópicos para dormir, embora a maioria durma em praças, sob marquises de lojas e em prédios abandonados. "À noite a praça é nossa!", como nos disseram, sinaliza a mudança que as pessoas imprimem a esses lugares. Durante o dia, não podem ocupá-las como os demais cidadãos, mas, à noite, as praças se tornam abrigos e palco de encontros e desencontros, conflitos e trocas, amores e cuidados. Também lugar de violência, sobretudo policial.

As ocupações obedecem a uma sazonalidade. Entre $20 \mathrm{~h}$ e $6 \mathrm{~h} 30 \mathrm{~min}$, muitos desses lugares se transformam em verdadeiros dormitórios ao ar livre. Quando o dia começa, pode-se encontrar ainda muitas pessoas dormindo, outras despertando lentamente, deixando ver o processo de transformação dos espaços. "Privatizados" durante à noite, momento em que ocultavam a condição de espaços públicos, ao dia, tais lugares reassumem a função normativa. A condição de liminaridade que opera na passagem dia-noite pode ser assim descrita: aos poucos, as praças, que antes fervilhavam de comerciantes e transeuntes, transformam-se. Sobre papelōes, colchões velhos, lençóis surrados ou sob o chão liso, as pessoas também vão se misturando e compondo outro cenário. A maioria tem junto ao corpo garrafas pet ou de bebidas e seus poucos pertences: algumas sacolas de plásticos, mochilas ou bolsas, que também colocam sob a cabeça, como modo de protegê-los de algum provável roubo ou como apoio para a cabeça. Muitos se agrupam, enfileirando-se, uns ao lado dos outros, lembrando o esquadrinhamento sobre o qual fala Foucault (1987), para fins do controle dos corpos. As pessoas dormindo ladeadas parecem buscar proteção para seus corpos e suas vidas: juntas, são menos vulneráveis aos perigos que a noite traz. Entretanto a proximidade também as leva a inventar modos de viver a intimidade e a sexualidade, como ouvimos, certa vez, de um casal homossexual: "Debaixo do nosso papelão, nós fazemos mil e uma utilidades". 
O que a noite procura apagar reaviva-se à luz do dia, quando diferenças se acentuam sob a norma reguladora dos espaços. É o momento em que alguns serviços se alternam nas funções de assistência ou repressão. Instituições religiosas ou filantrópicas servem uma sopa ou "quentinha" em alguns desses pontos, durante dias alternados da semana, em horário que coincide com o fechamento do comércio local. Muitas pessoas permanecem nas praças durante grande parte do dia, alguns trabalham como flanelinhas ou vigilantes de veículos, outros mendigam ou "mangueiam" (um tipo de mendicância mais convincente).

Nessa frágil e corporal demarcação de território, esses espaços são facilmente ocupados nos dias seguintes por outras pessoas, fazendo da provisoriedade uma marca da vida experimentada nas ruas por esses nômades urbanos, que não estão vinculados nem se identificam como ocupantes de um espaço geográfico fixo, nem mesmo para dormir, trocando de praça ou de ponto sucessivas vezes, com exceção dos "moradores de rua", que improvisam suas cassas sob viadutos ou outros espaços de passagem.

Todos carregam a "casa" nas costas, em bolsas ou mochilas nas quais levam tudo o que têm, sobretudo documentos, bens preciosos sem os quais não acessam nenhum serviço público. Sua perda, roubo, extravio ou destruição causa danos pessoais, contribuindo para o aumento e solidificação da exclusão. Ao não poderem atestar "que são quem dizem ser" pela ausência de um documento de identificação, perdem direitos legais, têm sua liberdade e mobilidade restringida e o acesso a bens e ao consumo limitado. A falta de "papéis" de identificação faz com que se tornem, ainda mais, anônimos perante o Estado e, portanto, menos controlados, o que implica, paradoxalmente, em mais exclusão (Peirano, 2009).

As práticas de higiene ou os cuidados com o corpo apontam o limiar tênue entre privacidade e exposição. A ausência de banheiros públicos os faz lavaremse precariamente e fazerem suas necessidades fisiológicas em plena rua ou em pontos comerciais, postos de gasolina, canteiros de obras e praças. Algumas vezes, os proprietários de estabelecimentos comerciais lhes fornecem água para beber, tomar banho e lavar suas roupas e pertences.

Observamos que, mesmo nesse cenário de precariedade e vulnerabilidade, há uma multiplicidade de práticas corporais. As mulheres e as travestis, em geral, são vaidosas: gostam de se maquiar, pintar as unhas, os cabelos e usar bijuterias. Há também muitos corpos tatuados, tanto de homens quanto de mulheres e de pessoas transgêneros, reiterando as associações negativas com o uso de drogas e vagabundagem.

De acordo com Frangella e Rui (2017), a vivência e convivência nas ruas, não somente entre as pessoas, mas também com os espaços, objetos e animais, 
produzem corpos precários, com marcas que se imprimem na pele, dentes, cabelos, olhos, unhas, ouvidos, mãos e pés, e sobretudo, no cheiro que impregna corpos e roupas, resultado do contato com plástico, papelóes, cobertores sujos e com o chão, indicando "o grau de interpenetração entre estes e os limites espaciais sobre os quais permanecem" (p. 33). Marcas de pancadas, facadas, queimaduras também são comuns e expressam conflitos cotidianos. Essa "corporalidade precária", segundo as autoras, profundamente marcada pela condição de vida, varia em intensidade conforme o despojamento de bens e o acesso a equipamentos que propiciam oportunidades de cuidado e higiene. A experiência indica um imbricamento entre corpo e cidade, produzindo "corpos abjetos resistentes" ante as condiçôes socioeconômicas e imposiçôes do poder urbanístico, redesenhando paisagens e espaços nos enfrentamentos aos poderes e saberes constituídos em torno dessa população (Frangella \& Rui, 2017, p. 35).

Essa produção do corpo remete à noção de habitus (Bourdieu, 1983) como sistema de disposições duráveis e internalizadas que permite a classificação dos agentes dentro de um campo e que, integrando experiências passadas, funciona a cada momento como uma matriz de percepções, apreciações e ações. De fato, essas pessoas têm uma estética incorporada como uma segunda natureza, pela qual são comumente identificadas e discriminadas, sendo não raramente alvo de abordagens e agressóes arbitrárias, inclusive, ou sobretudo, pela polícia.

Ao contrário das representaçôes de vadiagem e vagabundagem, que estão associadas a não participação no mundo do trabalho, muitas pessoas em situação de rua ganham a vida exercendo algum tipo de ocupação. Muitos desenvolvem atividade regular, sobrevivendo do trabalho precário: são vigias, cabelereiros, artesãos, flanelinhas, muitos dos quais com ponto fixo e, às vezes, até com renda estimada. Nesses casos, dormem em albergues, comem em equipamentos públicos ou filantrópicos e mantêm uma rotina diária. Há quem consiga alugar um quarto onde pode dormir, tomar banho, fazer amor, ter alguma privacidade, mas a renda não é suficiente para prescindir dos serviços públicos ou filantrópicos. Assim, embora não morem nas ruas, delas extraem condições básicas de sobrevivência: o trabalho e a comida.

Há os que nunca pedem, nem mangueiam, nem mendigam: acham indigno ou têm vergonha de fazê-lo e vivem à procura de algum "estouro" (doaçôes) nas ruas ou de comida nos serviços públicos ou filantrópicos, já que vagas para dormir é mais difícil, com longas filas de espera. Há ainda os que fazem pequenos bicos: com o que ganham com a mendicância ou com mangueio, compram balas, canetas, água mineral e outros artigos que revendem em ônibus ou nas praças; carregam compras nas portas de mercadinhos, lavam vidros de carros em sinais 
de trânsito, indicam vagas e "pastoram" carros. Outros são catadores de material reciclável, descartados no lixo ou em inúmeros pontos da cidade.

A despeito da condição de extrema pobreza e da vulnerabilidade comum a todos, a desventura de viver em grandes cidades à mercê da sorte faz com que muitos aleguem a necessidade de se "tornarem uma família nas ruas, já que perdemos as nossas" e contam histórias de solidariedade e ajuda mútua no enfrentamento das adversidades. Há também quem fale sobre os conflitos, ameaças, brigas e rivalidades, sem esconder o rancor e a acidez de críticas a seus pares, nomeando os que não trabalham de "vagabundos e marginais" que causam prejuízos para outras pessoas que "são de rua, mas são gente de bem".

Certamente as misérias cotidianas do mundo (Bourdieu, 2012), que se tornam lastro comum de tantas existências diferentes, mas unificadas pela exclusão, agora naturalizadas e de algum modo compartilhadas, produzem laços de solidariedade. A batalha pela comida diária é muitas vezes coletiva, produzida por eles mesmos com restos doados por restaurantes ou feirantes, o que parece ser uma resposta à passividade da espera, como dizem: "Pra que ficar esperando pelo que não vem?”. Apesar desses momentos de partilha, viver nas ruas ou estar em situação de rua é uma experiência de solidão: não têm amigos ou pessoas em quem confiar no dia a dia, "só conhecidos". A experiência não apenas de estarem sós, mas de serem sós, não exclusivamente de carências ou faltas absolutas, materiais e afetivas, mas de perda de realidades e relacionamentos significativos; experiências de abandono e desamparo, de desencontros com os outros e às vezes, consigo mesmo (Pais, 2006).

Há também, de um lado, recusa e ociosidade e, de outro, acomodação e passividade, como dois conjuntos de práticas pendulares. As primeiras aparecem como contestaçôes, ainda que não politizadas, de modos de vida ligados ao trabalho e ao consumo, podendo estar também vinculadas à revolta pelas desigualdades ao acesso a serviços, bens e consumo. São pessoas que portam uma espécie de "sociabilidade de evitação": de difícil acesso, de pouca conversa, parecendo adotar o ócio como estilo dominante de vida, inventando e improvisando, a cada dia, um jeito de sobreviver. Além das atividades anteriormente mencionadas, alguns comentem furtos e roubos, e ficam por muito tempo a nada fazer, vendo o tempo passar, pois são avessos à regulação do mundo do trabalho. As segundas lembram vidas amalgamadas nas condições imediatas de sobrevivência de pessoas que se tornaram quase farrapos humanos e parecem habitar corpos que não mais thes pertencem, numa destituição de tudo. Vidas também relacionadas ao uso abusivo da droga e a seu consumo/venda ilegal, que aparecem como motivos simultâneos de ida para as ruas e modo de suportá-la. É preciso dinheiro para manter o vício, e isso pode custar investimentos e riscos que estão ligados, também, ao 
rompimento ou fragilização dos vínculos familiares e de outras relações afetivas. Algumas dessas situaçôes remetem ao esfacelamento das regras de sociabilidade e o vazio das noções de direito e legalidade (Telles, 2010). Outras situações também se apresentam como prenhes de sofrimentos e impotência por parte de quem as vive: "A pior prisão é a consciência da pessoa". Alguns, ao relatarem crimes e delitos, "confessam" o profundo sofrimento por esse modo de vida, inflingindo a si mesmo penalidades extremas, entre as quais padecer na errância das ruas. Quase todos, enfim, vivem de arranjos e composições que se enredam entre a vida na rua e da rua, sempre dissonantes e desviantes dos parâmetros normalizadores do habitar a cidade: ter endereço, emprego e ser consumidor.

Por fim, encontramos quem diz seguir as normas morais rigidamente, ao afirmar, com orgulho, que não tem qualquer vício, como que expondo um troféu ao próprio comportamento em comparação aos outros: "Sou católico, não bebo, não fumo, sou trabalhador!”. Ou, no outro polo, quem faz uso abusivo do álcool de outras drogas, mas conserva o dever moral e a honra junto à família: "Não volto pra casa pra não envergonhar minha filha”.

A vida colada ao instante tem urgências cotidianas que determinam percursos e conquistas diárias descontínuas e precisam ser (re)inventadas diariamente. Dois sentidos de urgência parecem se contrapor: de um lado, a ação de instituições acompanhadas de intervenções em nome da segurança e ordenação dos espaços e, de outro, a carência baseada em situações extremas de vulnerabilidade. Esse descompasso de urgências (De Lucca, 2016) talvez traduza melhor a situação do que a percepção de "ausência e presença do Estado" veiculadas em alguns discursos. Nesse sentido, torna-se importante analisar as práticas institucionais.

\section{POR DENTRO DOS MUROS, OS EMPAREDAMENTOS INSTITUCIONAIS}

Quando criada, em 2009, a PNPSR, juntamente com outras políticas afirmativas, foi vinculada à Secretaria de Direitos Humanos da Presidência da República (SDH). O momento político em que ocorreu sua criação era bastante favorável, tendo em vista o compromisso do governo federal, à época, com a consecução de um Programa Nacional de Direitos Humanos, que se consolidava no Brasil pela implantação e realização de inúmeras políticas públicas setoriais e identitárias. Por elas, a bandeira da defesa dos direitos humanos ampliava seu objeto em relação a pautas anteriores do período da ditadura militar e ao processo de redemocratização do País, centrada em denúncias de violação de direitos pelo Estado, sobretudo referentes ao combate à tortura, aos abusos da ação policial e a outras situações nas quais o Estado, por infração ou omissão, era 
responsabilizado como autor da violação dos direitos humanos. Agora, seu foco se espraiava para outros temas: questôes de gênero, étnicas, geracionais, religiosas, etc., que alargaram a noção de violência institucional e de responsabilidades individuais frente à violação de direitos humanos, não mais circunscritas ao âmbito do Estado. Nesse contexto, por um lado, a noção de sujeito universal de direitos se ampliava e buscava sua efetivação através dessas políticas. Por outro, o novo contexto também implicava o risco do acirramento de uma concepção de direitos humanos liberal, que atribui aos indivíduos a responsabilidade por sua violação e ao Estado a função de punir os violadores desses direitos e de garantilos às vítimas.

De qualquer modo, aquele foi um momento de avanços, conquistas e possibilidades. O projeto em curso de efetivar um Plano Nacional de Direitos Humanos com financiamento do governo federal, entretanto, foi abortado pelo impeachment da presidenta Dilma Rousseff. A ruptura teve um drástico impacto sobre as políticas públicas, cuja principal consequência foi a criminalização dos movimentos sociais e a desarticulação dessas políticas, desde as mais consolidadas, como o SUS, até as mais recentes, como a ainda incipiente PNPSR.

Após uma década da criação da PNPSR, poucos serviços e dispositivos foram criados no âmbito do SUS e do SUAS. Os que existem permanecem em larga medida embasados na lógica caritativa-punitiva, o que desemboca em ações calcadas no preconceito, na estigmatização, no assistencialismo e muitas vezes, na violência física e simbólica contra drogaditos, pessoas com sofrimentos psíquicos, sem instrução ou com afetos e sexualidades divergentes dos padrões normativos. Além disso, quase não há iniciativas voltadas para a construção de políticas de habitação e trabalho, que apontariam mudanças mais resolutivas para essa população, num país onde "há mais casas sem gente do que gente sem casa”.

Contudo é inegável que, mesmo com a frágil criação de uma PNPSR, esse segmento marginalizado da população passou a ocupar um lugar de destaque no debate político, sobre o qual se produziram inúmeros saberes: médicos, jurídicos, assistenciais, etc. (Rui, Martinez, \& Feltran, 2017). Entretanto a excessiva burocratização e seus efeitos deixam esses serviços muito longe de serem instrumentos de garantia de direitos dessa população. Isso, sobretudo, se consideramos os modos díspares de viver das pessoas em relação aos funcionamentos institucionais, nos quais tempos e espaços regulamentados escapam ao modo como, fora de seus muros, a vida cotidiana é vivida. Nesta, a relação tempo-espaço é definida pela impermanência e qualificada como norma desviante. A distância entre o vivido e as tentativas de regulação é enorme, 
demonstrando o hiato de "urgências" e a não apreensão pelos serviços públicos das condiçôes subjetivas que permeiam o cotidiano dos que habitam as ruas.

Alguns fatos ilustram a situação. Nas duas capitais pesquisadas, as pessoas costumam ficar muito tempo nas calçadas dos serviços, esperando sua abertura, tanto pela manhã quanto no fim da tarde, sem proteção do sol e da chuva. Em quase todos os serviços nas duas cidades, o acesso é barrado por grades nas portas, que estão sempre fechadas com cadeados, mesmo no horário de funcionamento. Os horários de abertura e fechamento são rígidos e, enquanto se espera, não é possível usar os banheiros nem beber água. As vagas são muito limitadas e costuma-se deixar reservas caso haja alguma demanda de hospitais ou do Ministério Público, para abrigamentos de urgência. Desse modo, sempre sobram algumas, enquanto as pessoas que não conseguem entrar se apinham nas calçadas em frente aos prédios, para dormir. Os quartos são coletivos, e muitos usuários se queixam de dormir ao lado de pessoas que não conhecem. Em uma das cidades, a hora da entrada é acompanhada pela presença da Guarda Municipal, que fica ali de prontidão "para impor a ordem" e garantir a segurança dos funcionários. Nessa mesma cidade, as pessoas são revistadas quando entram, sendo para isso utilizado um detector de metais, que veio substituir um bafômetro que regulava o acesso, fatos amplamente contestados: "Como suportar a vida nas ruas no seco?". Perguntam os usuários de álcool. "Como viver nas ruas sem um canivete, uma faca, uma tesoura?", indagam os que trabalham como artesãos, os que fazem bicos e os que nada fazem, "Mas precisam se defender". As dificuldades de acesso aos serviços públicos ou filantrópicos de pernoite são muitas: em grande parte, pelo número reduzido de vagas que não comporta toda a demanda; em razão da existência de regras referentes ao cumprimento de horários e condutas, fazendo com que muitos prefiram "a liberdade da rua"; outros ainda relatam dificuldades nas relações com os funcionários, sentem-se discriminados ou alvo de preconceitos, como as travestis, que, em determinada unidade, não podem usar o nome social nem banheiros e dormitórios femininos.

Em nenhuma das cidades, os regimentos internos de funcionamento dos serviços foram construídos com a participação dos usuários, de modo que as sanções às infrações e às normas (como expulsão e suspensões) são executadas sem que muitos tenham conhecimento delas e ainda decorrentes de motivos banais. Algumas narrativas podem ilustrar essa questão: em determinado serviço, um usuário dividiu sua refeição com um companheiro que não havia conseguido vaga naquele dia, passando-lhe um pouco de comida pela grade da porta de entrada. Em resposta à sua solidariedade, foi suspenso por 30 dias. Barreiras de acesso aos serviços foram criadas em uma das cidades: a exigência de exame 
de HIV e atestado de cura de tuberculose; declaração de acompanhamento psicológico ou por parte do CAPS AD ou Alcoólicos Anônimos, no caso de alcoolistas e dependentes químicos, e não há vagas de acolhimento noturno para famílias.

Ressaltamos, entretanto, que não se trata de demonizar gestores e funcionários, como advertem Gama Júnior (2019) e Medeiros (2020), reiterados em nossas próprias entrevistas com os profissionais. Assim como a população de rua não é uma categoria homogênea, também os operadores institucionais são diferenciados. Muitos deles se sentem frustrados, impotentes e adoecidos pelas condições de trabalho: as instalações são, muitas vezes, precárias, não há insumos suficientes para atender às demandas (veículos, materiais, alimentação, etc.); os salários são baixos, muitos contratos são temporários, o que implica numa rotatividade de profissionais nas equipes, desarticulando ações e provocando ruptura de vínculos com os usuários, o que também tem impactos sobre a construção de projetos de vida para aqueles que desejam a saída das ruas; não há autonomia para a ação e nem participação na tomada de decisões, das quais são geralmente executores. Muitos profissionais se esforçam por resolver situações de saúde, desemprego, drogadição e familiares, às vezes usando seus próprios recursos e extrapolando suas atribuições, sem encontrar respaldo na rede de atendimento. A carência e, ou, fragilidade dessa rede de apoio é fato no qual muitos esbarram, além da falta de articulação entre os serviços, que não funcionam intersetorialmente.

É possível constatar, entretanto, que outros profissionais se encastelam numa posição arbitrária de confronto com os usuários. São, por vezes, preconceituosos, intolerantes e endurecidos, como discutimos acima. Além disso, a ausência de espaços coletivos de discussão faz com que se acirrem essas tensões entre quem atende e quem é atendido, de modo que alguns usuários defendem as punições e uma disciplina rígida, condenando seus pares por desobedecerem às normas, evocando, paradoxalmente, a necessidade de mais controle sobre os corpos e sobre as vidas nas ruas.

Esses fatos mostram, como na execução das políticas públicas, os trabalhadores (sejam gestores ou outros profissionais) são condicionados pelas prerrogativas e limites que a burocracia impõe e que incidem sobre seus próprios corpos, uma vez que a impessoalidade é seu principal efeito: um sistema no qual pessoa alguma pode ser plenamente responsabilizada, tornando-se, como adverte Arendt (2001), "o domínio de ninguém" e, por isso, "uma máquina de difícil destruição" (Weber, 1984). A burocracia materializa a face perversa do capital, baseada na divisão do trabalho, na especialização de funções, na tecnologia da informação, nos sistemas de gestão, nos protocolos de qualidade, em normas, 
regras e hierarquias bem definidas, peças-chave para a expansão do sistema capitalista e formas de dominação que ele engendra (Faria \& Meneghetti, 2011).

Hoje a burocracia adquiriu novas roupagens pela expansão do capital financeiro, atrelado a uma tecnoburocracia cada vez mais especializada, globalizada e potente, que, aliada às habilidades, competências e especialidades, estimula a concorrência e disputa entre trabalhadores e serviços. O que interessa apenas às instituições e não às pessoas, com suas singularidades, atesta o sentido pleno da burocracia já pensada em Weber. Nesse cenário, os potenciais usuários são alvo de invisibilidades, transformam-se em estatísticas, número de atendimentos; valem pelo quanto produzem ou consomem, processo que, no campo das políticas públicas, representa um distanciamento progressivo entre os objetivos e metas que lhes deram origem e o modo como se opera ao fim do percurso da intervenção. Esse processo está inserido na maneira como a sociedade, formada por uma rede de instituições, materializa-se em organizações sociais, sob a égide do Estado, como uma grande organização burocrática (Motta, 1981). Seja no campo das políticas públicas, seja no âmbito das organizações empresariais, "as finalidades do Estado são as da burocracia e as finalidades desta se transformam em finalidades do Estado", como afirma Tragtenberg (1974, p. 24). Em síntese, gestores e executores das políticas públicas fazem a máquina do Estado funcionar (Monteiro, Coimbra, \& Mendonça Filho, 2006), instituindo um tipo de lógica cujo sentido de funcionamento elimina variaçôes, nuances e sensibilidades. Ela produz capturas de indivíduos e eliminações de agências particulares. Cada ação pontualiza o segmento de um conjunto, e a imagem da máquina traduz bem o encadeamento de ações do processo.

\section{NÓS E OS OUTROS: AS MARCAS DA INTOLERÂNCIA À DIFERENÇA NA CIDADE}

Em $A$ cidade dos outros, Venturini (2009, p. 204) faz um paralelo entre a mudança de cenário produzida pelos loucos que transitavam nas cidades da Itália, após a Reforma Psiquiátrica naquele país, e os refugiados que passaram a ocupá-las posteriormente. Parafraseando o autor, diríamos que as pessoas em situação de rua, que ocupam centros urbanos de nossas cidades para nelas ou delas viverem, são "a interface entre dois mundos: o lugar onde se concretizam a solidariedade ou a compaixão, de um lado, e o racismo, a intolerância e o medo, de outro". Sobre elas, as representaçôes aparecem divididas em dois blocos: a) quem trabalha com esse público por compromisso, missão, militância, compaixão ou afinidade as vê como cidadãs, com direitos negados, que devem ser autônomas e protagonistas, visão também oscilante na direção da vitimização; b) os que 
"trabalham por obrigação", a polícia, muitos executores de políticas públicas e mesmo pessoas de instituiçôes religiosas e, sobretudo, aquelas que se relacionam compulsoriamente por serem vizinhos ou transitarem pelos mesmos espaços, as interpretações são muito depreciativas, preconceituosas e discriminatórias. De um lado, "nós", as pessoas de bem, residentes ou comerciantes antigos em locais agora ocupados por "eles", do outro lado, os que invadiram as ruas e as tornam "imundas, fedidas, perigosas e intransitáveis". De um lado, "nós", os defensores da ordem, da tradição e dos bons costumes; do outro, "eles" que, alterando o cenário urbano, de modo condenável ou conturbando o funcionamento esperado das instituiçóes, fazem com que os verdadeiros cidadãos, aqueles que têm direito à cidade pelo critério da antiguidade e produtividade, tenham de mudar rotinas e percursos ou se privem do livre acesso de ir e vir. Vistos como os depositários das mazelas da cidade, encarnam no próprio corpo e, em suas vidas errantes, aquilo que se considera que "os outros" produzam: anomia, violência e desintegração. Por isso, justifica-se seu extermínio, em práticas higienistas que se atualizam e se reinventam tentando evitar a "mistura" entre o cidadão urbano e os outros. O par "estabelecidos-outsiders" (Elias \& Scotson, 2002) é reconhecido em sua polaridade excludente, e, nesses casos, as imagens sobre "nós e eles", às vezes, acirram-se como "nós ou eles", e estão presentes não só nos serviços públicos que os atendem, mas também em algumas instituições filantrópicas, fazendo com que suas ações sejam muito distanciadas da "vida como ela é", fora dos muros institucionais. Em outros casos, refere-se também ao fato de que os proprietários de comércio, a vizinhança e a população em geral não toleram a mistura de atividades e funções (Barreira, 2016), preferindo isolar os diferentes que "contaminam" o ambiente.

Como fazer os serviços públicos funcionarem escapando da universalização das normas ou da burocratização para que possam atender públicos específicos e como garantir o direito de habitar a cidade de modo não usual? Como nela circular e nela ou dela viver em confronto, ou ao lado de representações e práticas tão discriminatórias?

Uma vez que a burocracia é necessária à organização da vida social, no âmbito das instituições, organizações, empresas, partidos políticos, sindicatos, movimentos sociais, etc., que necessitam de regras, normas, trabalho especializado e hierarquia para poder funcionar, dela não se pode prescindir. Pelo contrário, ela é um elemento importante para a ordem democrática e parte central da atividade política no mundo contemporâneo. $\mathrm{O}$ grande desafio das democracias é combinar a ação do Estado na gestão das políticas públicas com os princípios democráticos de inclusão de atores políticos nas tomadas de decisão e sua consequente responsabilização (Abrucio \& Loureiro, 2018). 
Entretanto é preciso estar sempre atentos a combater os efeitos perversos da burocracia, como alertava Tragtenberg (1974). Agregando, de modo indissociável, discussão acadêmica e militância política, ele acreditava que essa tarefa seria possível pela construção de um pensamento crítico baseado em práticas libertárias. Ao produzir autonomia, essas práticas se contrapõem aos modos autocráticos e dominadores de exercício de poder e à forma como a máquina do Estado funciona, atingindo todos os aspectos do comportamento social, econômico, político, sexual e afetivo (Tragtenberg, 1989). É importante reconhecer, pois, que as limitações impostas pela relação entre capitalismo e burocracia não invalidam pensar na possibilidade de ampliar espaços de reconhecimento de singularidades e outros modos de intervenção. Construir o coletivo, escapando às naturalizações que serializam pessoas, é possibilidade de experimentar outros modelos de gestão/atenção e de executar políticas públicas, no plano micropolítico, "com" as pessoas e não "para" elas, fazendo da partilha e não da homogeneidade o lastro para a construção do comum (Barros \& Pimentel, 2013).

A condição errante de homens e mulheres andarilhos, que nomadizam nas cidades, fala de necessidades radicais e insuportáveis da vida cotidiana, como afirma Martins (2008, p. 107) e convoca a outro projeto de sociedade. Projeto no qual se "anunciam as possibilidades contidas nas utopias, no tempo que ainda não é, mas pode ser. Para isso é preciso juntar os fragmentos, dar sentido ao residual, descobrir o que ele contém como possibilidade não realizada”, o que vai de encontro aos modos burocratizados de agir das políticas públicas aqui descritas, quando se fecham em seus muros e se distanciam da vida cotidiana. Mas, enquanto imperar o domínio da impessoalidade produzido pela burocracia, enquanto não for possível pensar em produzir uma experiência de "nós", feito por redes de sociabilidades, capazes de produzir o comum (com-um) e não apenas por espaços que se interligam por instituições ou circuitos urbanos, sempre haverá confinamento e encarceramento institucional ante os graves problemas urbanos, entre os quais o da segurança e o medo do outro, tomado como inimigo, tanto nos espaços fechados das organizações sociais quanto nos usos da cidade.

\section{CONSIDERAÇÕES FINAIS}

Os conflitos que, muitas vezes, permeiam o cotidiano de quem vive nas e das ruas, e entre essas pessoas e os modos de funcionamento institucional dos serviços que os atendem nos interpelam como um desafio ao exercício de pensar a cidadania e direito a uma vida digna. Aqui é preciso lembrar a cidade como polis, na qual os diferentes e a diferença tenham lugar. A diferença não 
como ameaça, mas como possibilidade de convivência e tolerância. $\mathrm{O}$ sentido de público subjacente ao próprio conceito de cidade perde a função conforme a miséria passa a ser a mancha excluída do quadro. As soluções institucionais burocratizadas revelam a não sintonia das categorias de espaço e tempo pensadas para pessoas que não se enquadram nesses parâmetros, o que nos levou a registrar o descompasso entre a intervenção das políticas públicas e as necessidades do público a elas dirigidas.

Muitos argumentos acerca dessas políticas se fixam na "ausência do Estado", mas não qualificam o debate sobre sua presença. Aqui procuramos privilegiar um dos maiores problema dessa relação: a tensão entre oferta de serviços versus necessidades e urgências do público. $O$ desencontro entre concepções diferenciadas de tempo e espaço pode ser avassalador para pessoas pouco afeitas às normas instituídas e que fazem desse "desvio" uma bússola na cidade. Nesse contexto, a violência torna-se a linguagem hegemônica geradora de um círculo vicioso de exclusão, com poucas possibilidades de rompimento, mesmo diante de movimentos de intermediação. As barreiras de acesso físico e simbólico nas cidades pesquisadas se constroem no preconceito, discriminação, violência e indiferença. Os desafios da rua são, portanto, os desafios da cidade: agregar histórias e dar suporte às diferenças. 


\section{REFERÊNCIAS}

Abrucio, F. L., \& Loureiro, M. R. (2018). Burocracia e ordem democrática: desafios contemporâneos e experiência brasileira. In R. Pires, G. Lotta, \& V. E. Oliveira (Orgs.), Burocracia e políticas públicas no Brasil: interseçôes analíticas. (pp. 23-57). Brasília: IPEA, ENAP, 2018. Recuperado a partir de http:// repositorio.ipea.gov.br/handle/11058/8560

Arendt, H. (2001). Sobre a violência. (3a ed.). Rio de Janeiro: Relume Dumará.

Augé, M. (2008). Não lugares: introdução a uma antropologia da sobremodernidade. Lisboa: 90 Graus.

Barreira, I. (2016). "Vazios" e "misturas": classificações socioespaciais sobre o centro da cidade. In C. Barreira, \& I. Barreira (Orgs.), Etnografias na cidade: redes, conflitos e lugares. Campinas: Pontes.

Barros, M. E. B., \& Pimentel, E. H. C. (2013). Políticas públicas e construção do comum: interrogando práticas Psi. Revista Polis e Psique, 2(2), 3-22.

Bourdieu, P. (1983). Questôes de sociologia. Rio de Janeiro: Marco Zero.

Bourdieu, P. (Org.). (2012). A miséria do mundo. (9a Ed.). Petrópolis: Vozes.

Butler, J. (2015). Quadros de Guerra: quando a vida é passivel de luto? Rio de Janeiro: Civilização Brasileira.

Certeau, M. (1998). A invenção do cotidiano: as artes de fazer. (Vol 1). Petrópolis: Vozes.

Decreto n. ${ }^{\circ}$ 7.053, de 23 de dezembro de 2009. (2009, 23 dezembro). Institui a Política Nacional para a População em Situação de Rua e seu Comitê Intersetorial de Acompanhamento e Monitoramento, e dá outras providências. Diário Oficial da União, Brasília. Recuperado a partir de http://www.planalto. gov.br/ccivil_03/_Ato2007-2010/2009/Decreto/D7053.htm

De Lucca, D. (2016). Morte e vida nas ruas de São Paulo: a biopolítica vista do centro. In T. Rui, M. Martinez, \& G. Feltran (Orgs.), Novas faces da vida nas ruas (pp. 19-43). São Carlos: EdUFSCar.

Elias, N., \& Scotson, J. L. (2002). Os estabelecidos e os outsiders. Rio de Janeiro: Zahar. 
Faria, J. H., \& Meneghetti, F. K. (2011). Burocracia como organização, poder e controle. Revista de Administração de Empresas, 51(5), 424-439.

Frangella, S. M. (2009). Corpos urbanos errantes: uma etnografia da corporalidade de moradores de rua em São Paulo. São Paulo: AnnaBlume, FAPESP.

Frangella, S., \& Rui, T. (2017). Corpos precários: apontamentos para a relação entre corpo e cidade. Politica \& Trabalho: Revista de Ciências Sociais, 47, 23-38.

Foucault, M. (1987). Vigiar e punir: nascimento da prisão. Petrópolis: Vozes.

Gama Júnior, C. (2019). Atravessamentos e transvesalizaçôes na vida de moradores de rua: reflexóes a partir de um lugar institucional no município de Aracaju-SE. (Dissertação de Mestrado). Universidade Federal de Sergipe, Programa de PósGraduação em Psicologia, São Cristóvão.

Lourau, R. (2004). O instituinte contra o instituído. In S. Altoé (Org.), René Lourau: analista institucional em tempo integral. (pp. 47-65). São Paulo: Hucitec.

Machado, R., Loureiro, A., Luz, R., \& Muricy, K. (1978). Danação da norma. Rio de Janeiro: Graal.

Martins, J. S. (2008). A sociabilidade do homem simples. São Paulo: Contexto.

Medeiros, F. C. (2020). No fio da navalha: entre a garantia de direitos e a higienização social nas políticas públicas para a população em situação de rua. (Tese de Doutorado). Universidade Federal do Rio Grande do Norte, Programa de Pós-Graduação em Psicologia, Natal.

Monteiro, A., Coimbra, C., \& Mendonça Filho, M. (2006). Estado democrático de direito e políticas públicas: estatal é necessariamente público? Psicologia \& Sociedade, 18(2), 7-12.

Motta, F. C. P. (1981). O que é burocracia. São Paulo: Brasiliense.

Neves, F. C. (1995). Curral dos bárbaros: os campos de concentração no Ceará (1915-1932). Revista Brasileira de História, 15(29), 93-122.

Pais, J. M. (2006). Nos rastos da solidão: deambulaçôes sociológicas. Lisboa: Ambar.

Pais, J. M. (2015). Sociologia da vida cotidiana. (6a ed.). Lisboa: Imprensa de Ciências Sociais. 
Peirano, M. (2009). O paradoxo dos documentos de identidade: relato de uma experiência nos Estados Unidos. Horizontes Antropológicos, 15(32), 53-80.

Rui, T., Martinez, M., \& Feltran, G. (2017). Nova face da vida nas ruas. São Paulo: Martins Fontes.

Telles, V. (2010). A cidade nas fronteiras do legal e ilegal. São Paulo: Fino Traço.

Tragtenberg, M. (1974). Burocracia e ideologia. São Paulo: Ática.

Tragtenberg, M. (1989). Administração, poder e ideologia. São Paulo: Cortez.

Venturini, E. (2009). A cidade dos outros. Fractal, 21(2), 203-222.

Weber, M. (1984). Economia y sociedade. (2a ed.). México: Fondo de Cultura Económica. 